\title{
Kylo Ren Was Redeemed: Star Wars Fans Rejoice and So Should Psychiatric Educators
}

\author{
Anthony P. S. Guerrero ${ }^{1} \cdot$ Vanessa L. Cunanan ${ }^{2}$
}

Received: 22 October 2020 / Accepted: 16 August 2021 / Published online: 16 September 2021

(c) Academic Psychiatry 2021

A long time ago (December 2019), in a galaxy far away (pre-COVID-19 pandemic Earth), Star Wars Episode 9: The Rise of Skywalker was released. Whether or not Kylo Ren would be redeemed was of interest for the authors, who have used the film series to discuss risk and protective factors for delinquency, violence, and other challenging behavior.

\section{The Skywalker Family (Anakin Skywalker Alias Darth Vader, Son Luke Skywalker, Daughter Leia Organa Solo, and Grandson Ben Solo Alias Kylo Ren)}

The Star Wars films featured The Force, an omnipresent energy field that directs everyone's actions [1]. The films described conflicts between the Jedi, who altruistically harnessed the "light side" of The Force for knowledge, peace, healing, and self-defense, and the Sith, who selfishly harnessed the "dark side" of The Force to promote fear, anger, hatred, aggression, and corruption. We use the terms "light" and "dark" purely in reference to the Force of Star Wars, first released in 1977, and not in reference to physical features and will guard against any reinforcement of stereotypes that "light" is good and "dark" is bad.

Episodes 1-6 described Anakin Skywalker, who became the Sith Lord Darth Vader following a traumatic loss and fear of future loss at a developmentally sensitive phase, and while under the influence of Sith Master Darth Sidious/ Emperor Palpatine [1]. Anakin Skywalker was subsequently redeemed by his Jedi son Luke Skywalker, who shared some risk factors with his father but who had mostly protective factors [1]. Episode 7 introduced Kylo Ren as a hardened

Anthony P. S. Guerrero

GuerreroA@dop.hawaii.edu

1 University of Hawai'i John A. Burns School of Medicine, Honolulu, HI, USA

2 Honolulu, USA villain who worked for the evil "First Order," reminiscent of Palpatine's Empire, and who killed his own father, Han Solo [2].

Over the course of Episodes 8-9 of the series, we learn that Kylo Ren, formerly Ben Solo, had originally been mentored by Luke Skywalker but felt betrayed by him. In this vulnerable state, he was deceived and manipulated by a new mentor, Snoke, into separating himself from his parents (Leia Organa Solo and Han Solo) and becoming a practitioner of the dark side of the Force, based in pain, anger, and aggression. He committed many evil acts, including murdering his father, but his parents and original mentor never gave up on him. They continued to reach out to him (often through magical interventions made possible by the Force), and he was ultimately able to return to the light side of the Force. This redemption occurred through a complicated and quasi-romantic relationship with Rey, a young Jedi-aspirant whom he tried to turn to the dark side at the charge of the ultimate evil mastermind of the series, Palpatine. Kylo Ren ultimately sacrificed himself to support Rey in confronting Palpatine.

\section{Potential Teaching Points}

Guerrero and Jamora [2] proposed that Episode 7 can help educators highlight certain tasks in caring for youth succumbed to violence and other disruptive behaviors:

- helping families to recognize adverse influences (e.g., addictive substances, brainwashing, threats of harm) and other risk factors;

- empathizing with the guilt that parents and family members feel when confronting the youth who rejects them; and

- using the biopsychosocial approach to ensure safety, remove the adverse influences, provide developmentally normal corrective experiences, and heal relationships. 
We build on these principles and highlight lessons from Episodes 8 and 9 that we believe are timely in keeping psychiatrists and trainees inspired to care for the most challenged patients. These lessons, which focus on attitudes in the education rubric, can complement evidence-based psychiatric practice guidelines [3-6].

\section{Lesson 1: Comprehensively Address Negative Influences and Erroneous Thinking}

Hatters-Friedman and Hall noted that Kylo Ren had significant risk factors for psychopathology and for committing parricide, as he did in Episode 7 [7]. He was prone to tantrums, had clouded thinking (like a drug's effect), rejected his family, and possibly had psychotic symptoms. Additionally, he was a young single male with access to a weapon.

Nevertheless, the factors that led to his redemption were as powerful as the factors that contributed to his fall. In Episode 9 , as his mother reached out to him prior to her death, he realized that she accepted him and that all of his previous beliefs originated from Snoke's manipulation. Seeing this reality helped him to join Rey in uniting against Palpatine, who was nothing but predatory and manipulative. Palpatine habitually created conflict - to the point of creating wars between a Trade Federation and elements of the Republic and manipulating apprentices to try to kill one another to advance his needs.

These aspects of the story highlight that psychiatric treatments, based on a biopsychosocial formulation, often require removal of negative influences (e.g., abusive or predatory figures, mind-altering substances), correction of erroneous thinking (e.g., through discussions of experiences that are emotionally corrective and that challenge negative assumptions), and identification of strengths and past positive experiences that facilitate openness to sponsorship, connection, and attachment. Furthermore, these aspects of the story highlight the need, in psychiatric care, to help families and healthcare teams to see through the chaos, distress, and splitting generated by a disruptive presence and to unite around a common goal.

\section{Lesson 2: Facilitate the Healing of Relationships Disrupted by Manipulation and/or Confusion}

One aspect of healing broken relationships involves belief that hope still remains for change and growth. Like Anakin Skywalker, Kylo Ren had people in his life who believed in his redeemability and who provided (even via distance or posthumously) a corrective emotional experience. Towards the end of Episode 8, Luke Skywalker did not destroy Kylo Ren, even as the latter attacked and stabbed the former. Luke Skywalker said (2:17:20): "Strike me down in anger and I'll always be with you. Just like your father." Instead of killing a mortal body (as it did with his father in Episode 7), Kylo Ren's lightsaber slipped right through Luke Skywalker, whose Force-enabled projection of his image over a distance caused enough distraction to allow the resistance forces to escape but also led to his own death via exhaustion [8]. Prior to disappearing, Luke Skywalker told Kylo Ren (2:18:21): "See you around, kid..." which, being a quote from Han Solo, likely further primed Kylo Ren to remember his father. As detailed below, in the subsequent Episode 9, Leia Organa Solo and Han Solo communicated their love, in contrast to any feelings he had of previous betrayal.

Another aspect of healing relationships is the centrality of forgiveness. In Episode 9, while in a lightsaber duel, Kylo Ren told Rey (1:16:56): "You wanted to prove to my mother that you were a Jedi... But you've proven something else. You can't go back to her now. Like I can't... The dark side is in our nature... Surrender to it." However, his assumption was wrong. His mother subsequently reached for the Force in "a final act of hope, and... With all the life and love and hope and forgiveness in her being... called out 'Ben!' “ [9] Hearing his mother, Kylo Ren dropped his lightsaber, which Rey then used to stab him. She promptly sensed that his mother had called him. Endowed with the uncommon skill to restore life, she risked her own life to heal Kylo Ren's mortal wound. Han Solo, speaking as a spirit, then expressed forgiveness to the son who killed him while manipulated by Snoke (1:25:03): "I miss you, son... Kylo Ren is dead. My son is alive." He called his father "Dad," hurled his Sith lightsaber into the sea, and then continued his mother's fight against the First Order.

Ultimately, forgiveness was something granted to Kylo Ren by those whom he harmed and something that he granted to those by whom he felt betrayed. As explained by Akhtar [10], forgiving does not necessarily equate to forgetting, as the memory of a trauma remains present at a preconscious level. Forgiveness is an active process that involves resolution of anger and unpleasant emotions associated with the memory and a changed attitude towards the perpetrator. Distinct psychological processes are involved for both the bestower and seeker of forgiveness. Forgiveness has neurobiological, cognitive, and social benefits [11].

While "forgiveness" may not be a core feature of most standard psychotherapies taught in psychiatry curricula, certain traditional family healing approaches explicitly incorporate forgiveness, through facilitated communication (with ground rules for emotional expression) among family members, discussion of perceived transgressions and impact, release of the conflict and hurt, and restoration of relationships [12]. A forgiveness protocol that follows the mnemonic "REACH" (recall the hurt, empathize, altruistic gift of forgiveness, commit to the forgiveness experience, hold on to the forgiveness experience) has also been designed for use in clinical settings [13]. 
These aspects of the story highlight that, within relationships, forgiveness and healing, which the clinician can play a role in facilitating, may be foundational in establishing mutual openness to other therapeutic interventions, especially in the face of chaos and conflict triggered by external stressors or disruptors.

\section{Lesson 3: Strengthen Positive Relationships at All Stages of Development}

Kylo Ren succumbed to the dark side because of manipulation during a developmental stage where parental support and sponsorship are needed [14] but where he instead perceived rejection by his parents and Jedi instructor/ Uncle Luke Skywalker. On the other hand, Kylo Ren's redemption became possible because his developmentally appropriate interest in a relationship with Rey became at least as important as whatever other goals young adult dark-side-of-the Force practitioners typically pursue. Similarly, in Episodes 5-6, Anakin Skywalker/Darth Vader was redeemed because he had, as an older adult, a developmentally appropriate interest in generativity and establishing a relationship with his offspring, Luke Skywalker [1]. Ben Solo's and Anakin Skywalker's fall and redemption illustrate the importance of relationships, throughout development, as a protective factor against psychopathology and destructive behavior.

In contrast, Palpatine must not have been subject to typical "human" development the way that the other redeemable villains were, and relationships truly did not matter to him. As he sucked Rey and Ben Solo's life force, he had no intention to be "sacrificed." Unlike Anakin Skywalker, Palpatine was willing to kill his offspring (Rey's father) and grand-offspring, Rey.

These aspects of the story highlight the importance, in psychiatric care, of strengthening relationships, especially those that foster healthy development at various stages. For example, children build trust and responsibility through positive relationships with parents, caregivers, and mentors. Adolescents and young adults further their capacity to care for and nurture others through positive relationships with peers and romantic partners. Older adults solidify legacy and meaning through positive relationships with offspring, other descendants, and mentees.

\section{Implementation in the Classroom}

In an educational forum focused on quality, safety, and systems of care, the first author has shown scenes from Episode 9 where Kylo Ren was forgiven by his parents and healed by Rey and where Kylo Ren demonstrated the depth of his redemption by helping Rey and saving her life as she confronted Palpatine. The group was asked questions on what these scenes made them think of, and what lessons they might be able to glean from the standpoint of clinical care in challenging circumstances. The first author guided the discussion towards themes of forgiveness, repairing relationships disrupted by a common adversary, and leveraging these healed relationships to confront the common adversaries (including the pandemic) that teams face in healthcare. While no specific data has been gathered, the first author's overall experience was positive, and group participation seemed to indicate interest and engagement in the topics.

We also believe that references to the Star Wars films' characters and stories may be used to teach trainees about child development, disruptive behavior disorders, violence prevention, and/or resilience. Given each film's length and the potential that lessons may come from more than one film, we suggest viewing, during seminars, brief clips, such as those referenced above, and referring the learners to view, with a psychiatric lens, the whole films during independent learning. Alternatively, in replacement of previously allowed "movie night" gatherings and in support of initiatives to enhance wellness and social connectedness in the face of a pandemic, larger film segments could be viewed as an educational watch party or group watch that facilitates sharing among learners and teachers.

\section{Conclusion}

Especially during these stressful times, we encourage educators to find fun ways to teach. Recalling material from pre-pandemic films may be one way to give hope and inspiration.

Comfort and skill with developmentally informed, safety-focused biopsychosocial formulations can prepare our trainees to care for youth stressed by pandemic disruptions. Commitment to strengthening relationships-notwithstanding physical separation-can help build future generations' resilience against pandemicrelated adversities. Awareness of how such disruptions can bring out the worst in people and in systems can help trainees to work patiently in settings that are afflicted by pandemic stress. Finally, forgiveness may be what we need to survive the pandemic's next phase and all of its impacts on well-being, work, and relationships.

May the Force be with us. 


\section{Declarations}

Disclosures On behalf of all authors, the corresponding author states that there is no conflict of interest.

\section{References}

1. Guerrero AP, Jamora MJ. The fall and redemption of people and systems: potential lessons from the "Star Wars" saga. Acad Psychiatry. 2007;31(6):485-90. https://doi.org/10.1176/appi.ap.31.6. 485.

2. Guerrero AP, Jamora MJ. Can Kylo Ren be redeemed? New potential lessons from Star Wars Episode VII. Acad Psychiatry. 2016;40(4):630-3. https://doi.org/10.1007/s40596-016-0565-4.

3. Buitelaar JK, Smeets KC, Herpers P, Scheepers F, Glennon J, Rommelse NN. Conduct disorders. Eur Child Adolesc Psychiatry. 2013;22(Suppl 1):S49-54. https://doi.org/10.1007/ s00787-012-0361-y.

4. Pilling S, Gould N, Whittington C, Taylor C, Scott S, Guideline development group. Recognition intervention and management of antisocial behaviour and conduct disorders in children and young people summary of NICE-SCIE guidance. BMJ. 2013;346:298. https://doi.org/10.1136/bmj.f1298.

5. Gorman DA, Gardner DM, Murphy AL, Feldman M, Bélanger SA, Steele MM, Boylan K, Cochrane-Brink K, Goldade R, Soper PR, Ustina J, Pringsheim T. Canadian guidelines on pharmacotherapy for disruptive and aggressive behaviour in children and adolescents with attention-deficit hyperactivity disorder, oppositional defiant disorder, or conduct disorder. Can J Psychiatry. 2015;60(2):62-76. https://doi.org/10.1177/070674371506000204.

6. Sagar R, Patra BN, Patil V. Clinical Practice Guidelines for the management of conduct disorder. Indian J Psychiatry.
2019;61(Suppl 2):270-6. https://doi.org/10.4103/psychiatry.India nJPsychiatry_539_18.

7. Hatters-Friedman S, Hall RC. Star Wars: the force awakens forensic teaching about patricide. J Am Acad Psychiatry Law. 2017;45(1):128-30.

8. Fry J. The Last Jedi: expanded edition (Star Wars). United States: Random House Publishing Group; 2018.

9. Carson R. The Rise of Skywalker: expanded edition (Star Wars). United States: Random House Publishing Group; 2020.

10. Akhtar S. Forgiveness: origins, dynamics, psychopathology, and technical relevance. Psychoanal Q. 2002;71(2):175-212. https:// doi.org/10.1002/j.2167-4086.2002.tb00010.x.

11. Fourie MM, Hortensius R, Decety J. Parsing the components of forgiveness: psychological and neural mechanisms. Neurosci Biobehav Rev. 2020;112:437-51. https://doi.org/10.1016/j.neubi orev.2020.02.020.

12. Hurdle DE. Native Hawaiian traditional healing: culturally based interventions for social work practice. Soc Work. 2002;47(2):183-92.

13. Clabby JF. Forgiveness: moving on can be healthy. Int J Psychiatry Med. 2020;55(2):123-30. https://doi.org/10.1177/0091217419 885468.

14. Alexander B. Interview with H. Spencer Bloch, MD, "Adolescent psychology." https://ongoodauthority.com/content/Adolescent\% 20Psychology\%20and\%20Development/Adolescent\%20Psychopa thology\%20and\%20Development.pdf (Accessed 1/26/2021)

Publisher's Note Springer Nature remains neutral with regard to jurisdictional claims in published maps and institutional affiliations. 